\title{
A NEW SUBSPECIES OF LITTLE BROWN BAT FOR ALBERTA
}

HUGH C. SMITH, Provincial Museum, Edmonton, Alberta, T5N 0M6, an DAVID B. SCHOWALTER, Alberta Fish and Wildlife Division, Edmonton.

During a survey of colonies of little brown bat Myotis lucifugus in Alberta it was observed that bats from colonies in southern Alberta differed in color and probably size from bats from colonies in central Alberta. As a result of these observations museum collections were made in order to compare bats from the two regions.

Table 1 lists the locations of colonies from which the collections were made which were used in this study. Specimens are deposited in the Provincial Museum of Alberta.

When compared in a series, bats from colonies in the south are lighter in pelage colouration than those bats from northern colonies. The dorsal pelage of southern bats ranges in colour from light brown (almost blond) to medium brown, a few very dark individuals have been observed in colonies, however, none of these are represented in the collections. The northern bats are darker, ranging from reddish brown to dark brown. The pelage of the southern bats appears flatter and without the sheen that characterizes many northern bats. Flight membranes on the southern bats are also lighter in colour. There is frequently a white margin on the trailing edge of the flight membrane that is not evident on bats from colonies in central Alberta.

Table 2 compares some measurements of adult female bats. The sample for each colony was at least six bats. The initial impression of smaller size of southern bats is not supported by measurements of tail length and head/body lengtl however, they are smaller in forear length and greatest skull length.

Direct comparison of weights bats from central and souther Alberta are difficult as weight varie greatly during the summer, howeve it is evident that the souther population tends to weigh less tha bats farther to the north (Fig. 1). Th two populations also differ in timin of birth. In central Alberta parturitio is largely concentrated in late Jun (unpublished data, Alberta Fish an Wildiife Division). Captures of bats a a large bat colony at Warner in dicated that parturition was only jus over half completed by 12 July 197 and still not complete on 21 Jul 1975. N. Previsich (pers. comm.) ha observed colonies near Lethbridge it which most of the young were borr in the latter part of July. On the othe hand pregnancies of bats anc development of juveniles in a colon: near Brooks observed in late Junt were similar to that of bats in centra Alberta. O'Farrell and Studier relate concentration of the time of par turition of Myotis, such as seen ir central Alberta, to adult female: having left hibernacula at ap proximately the same time, whereas a longer, variable period of par turition, as is seen in souther Alberta, is considered indicative o female bats leaving the hibernaculc over a greater period of time. ${ }^{7}$ If this is the case with little brown bats in Alberta the areas of hibernation 0 the central and southern populations would be expected to be different ir 
limate and be relatively distant from ne another.

Sex and reproductive structure of t least some colonies in southern lberta appear to differ from that of olonies known elsewhere. Of 51 dult bats captured at Warner 12 July 977,17 were pregnant or lactating emales, 24 were dry females and 10 vere adult males. Dry females and dult males seldom make up a ignificant proportion of individuals little brown bat nursery colonies nd their occurrence at Warner varrants further investigation. 5 Collections of adults at other olonies in southern Alberta during he summer and at Warner in early ummer are made up largely of eproductively active females, Ithough preliminary data indicates hat adult males are found more equently in maternity colonies than central Alberta.

Anderson, ${ }^{1}$ Hall and Kelson, ${ }^{4}$ and boper9 report three subspecies of Ayotis lucifugus in Alberta; Banfield2 eports two. Myotis lucifugus ucifugus, the most widely distributed ubspecies, generally is considered - occur over most of the nonhountainous portion of Alberta. It is medium sized Myotis aproximately $97 \mathrm{~mm}$ in total length vith a dull brown pelage and prownish flight membranes. ${ }^{9} \mathrm{M}$. I. lascensis is reported to occur in the outhwestern mountains. It is darker $n$ pelage and flight membrane olouration but similar in size to M. I. ucifugus. 8 Banfield does not conider this subspecies to occur in the rovince. ${ }^{2} \mathrm{M}$. I. pernox is known from he mountains from Hinton-Entrance vest to the Jasper area. It is reported have a larger skull than $M . I$. ucifugus and to have blacker flight embranes. 8 9 It appears unlikely at the population found in southern Iberta can be assigned to any of iese subspecies.
Table 1. LOCATIONS AND NUMBER OF SPECIMENS OF LITTLE BROWN BATS COLLECTED IN ALBERTA.

Location

No. Specimens

Atmore

17

Champion

21

High River

10

Lac La Biche

New Norway

Pigeon Lake

Schuler

Stony Plain

Vilna

Warner

10

10

9

6

8

21

In their review of Myotis, Miller and Allen indicate that the subspecies $M$. 1. carissima has a paler colour than M. I. lucifugus and that the "edges of the interfemoral membrane and parts of the posterior edge of the wing membrane may be whitish, sometimes forming a distinct border." 6 In view of this description of M. I. carissima, the similarity of measurements (Table 3), and the proximity to known occurrences of the subspecies (Fig. 2), we believe the little brown bats from the plains region of southern Alberta to be $M$. I. carissima. The reported Canadian distribution of $M$. I. carissima is the Okanagan area of southern British Columbia. ${ }^{3}$ Hall and Kelson show the northern range of the subspecies as terminating at the international boundary in Montana (Fig. 2). ${ }^{4}$ The extent of the distribution of the subspecies in Saskatchewan was examined by inspection of rabies-suspect bats from that province. None of these specimens are preserved in museums, and collections are needed to verify these results. Based on bats available to us we believe that $M$. I. carissima occurs over the non-mountainous portions of southern Alberta and southwestern Saskatchewan (Fig. 2). 


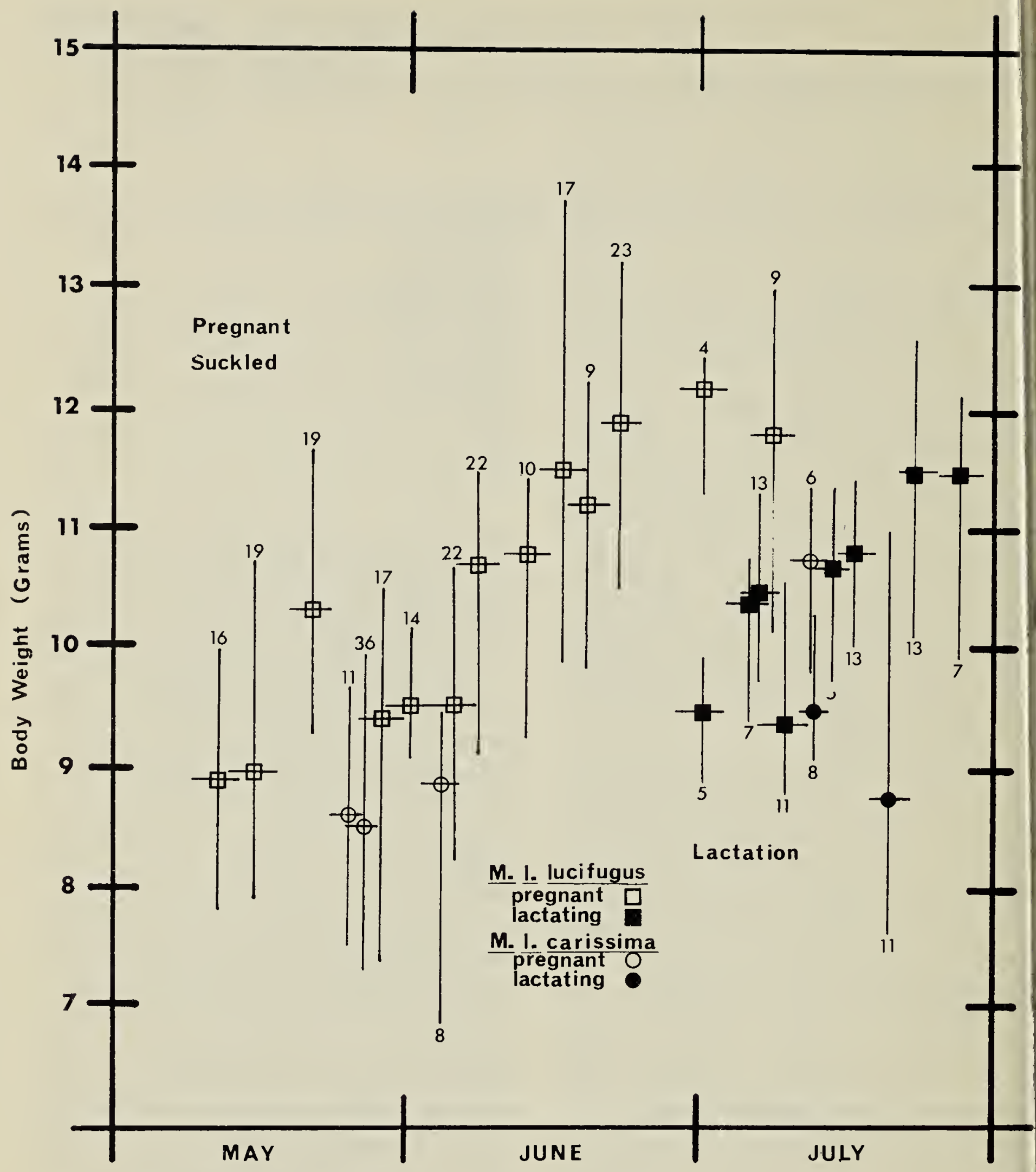

Figure 1. Summer weights of female Myotis lucifugus.

Table 2. SELECTED MEASUREMENTS OF ADULT FEMALE LITTLE BROWN BATS.

$$
\text { Northern Colonies }(n=8) \quad \text { Southern Colonies }(n=3)
$$

$\begin{array}{lllll} & \text { Range } & \text { Mean } & \text { Range } & \text { Mean } \\ \text { Tail } & 33-46 & 37.7 & 32-44 & 38.4 \\ \text { Head and Body } & 47-61 & 51.4 & 46.57 & 51.4 \\ \text { Dried Forearm } & 36.1-41.2 & 38.08 & 34.7-39.1 & 36.9 \\ \text { Greatest Skull Length } & 14.04-15.78 & 15.05 & 14.21-15.47 & 14.83 \\ 60 & & & & \text { Blue Jay }\end{array}$




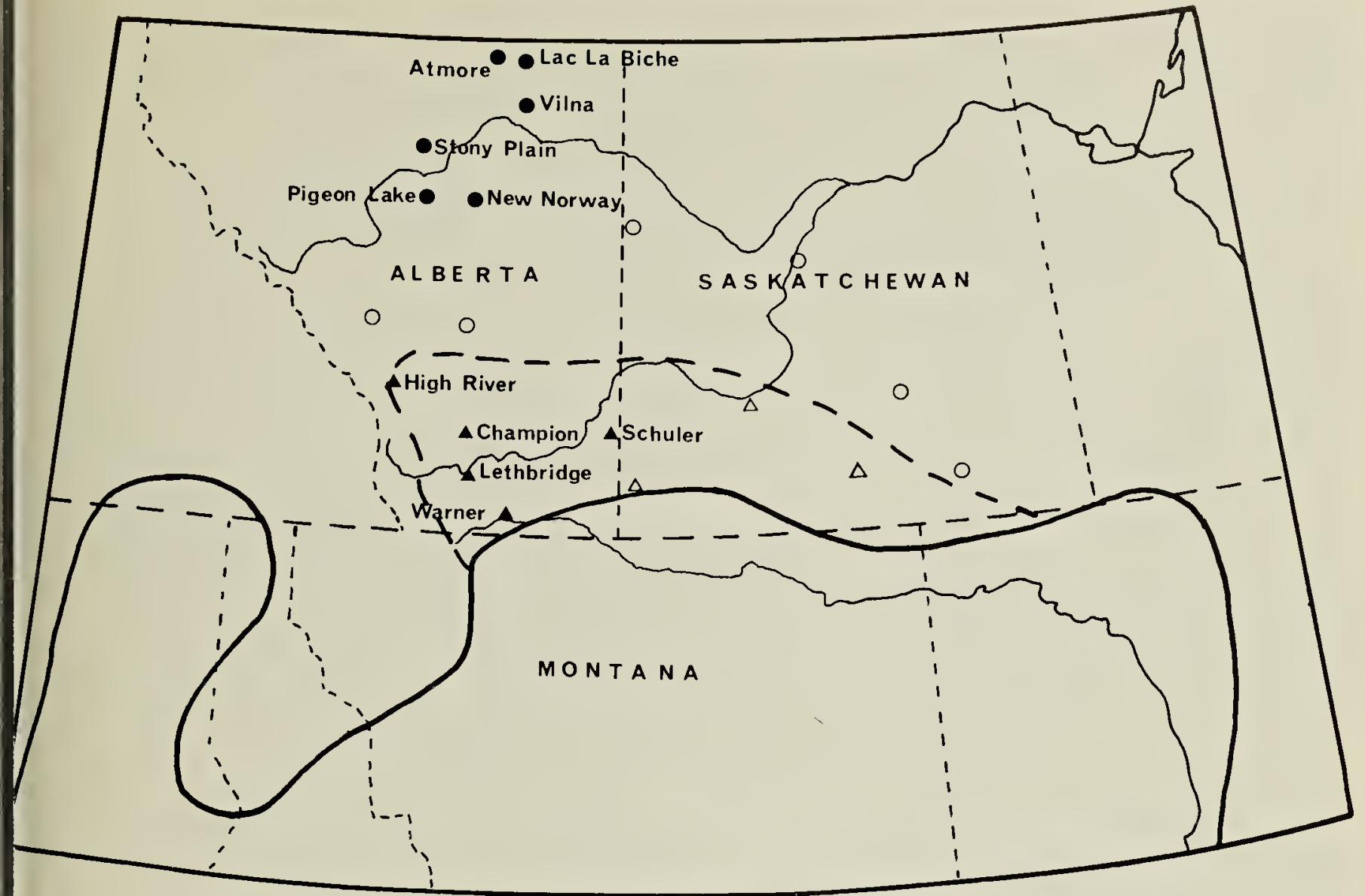

Myotis lucifugus lucifugus

Myotis lucifugus carissima

- Sample colony

$\triangle$ Sample colony

ORabies suspect

$\triangle$ Rabies suspect

jgure 2: Range of Myotis lucifugus carissima. Solid line as per Hall and Kelson (1959). roken line as proposed by the authors.

The Agriculture Canada Animal iseases Research Institute Vestern) gave us access to rabies ispect bats from Saskatchewan. ick Previsich's continued interest in ats and generosity with data have een outstanding. The Alberta Fish and Wildlife Division bat research program is funded through the Veterinary Services Division of the Alberta Department of Agriculture. The continued interest and support of $H$. Vance and $G$. Whenham is greatly appreciated.

able 3. COMPARISON OF SELECTED MEASUREMENTS OF MYOTIS JCIFUGUS CARISSIMA FROM NORTHERN UNITED STATES AND FROM DUTHERN ALBERTA.

$\begin{array}{lll} & \text { M.I. carissima } & \begin{array}{l}\text { M. lucifugus from } \\ \text { southern Alberta }\end{array} \\ \text { ail } & 38.4 & 38.4 \\ \text { ead/Body } & 49.1 & 51.4 \\ \text { ried Forearm } & 37.7 & 36.9 \\ \text { reatest Skull Length } & 14.95 & 14.83\end{array}$

Miller and Allen, 1928) 


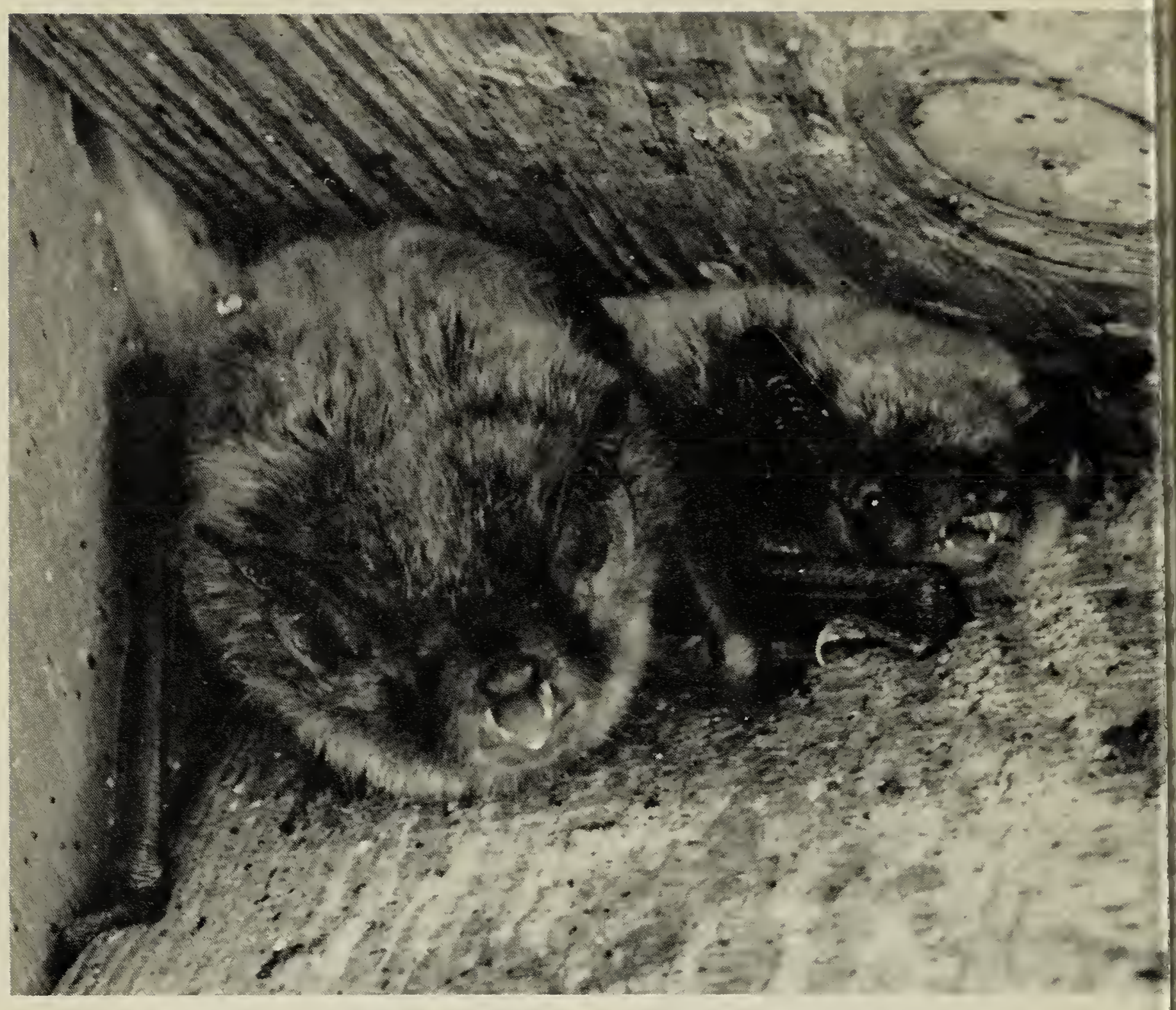

Little Brown Bat M. I. carissima at Warner, Alberta.

Lawrence D. Harde

${ }^{1}$ ANDERSON. R. M. 1946. Catalogue of Canadian Recent Mammals. Nat. Mus. Can. Bull. 102, Biol. Ser. 31. 238 pp.

2BANFIELD, A. W. F. 1974. The Mammals of Canada. University of Toronto Press, Toronto. $438 \mathrm{pp}$.

${ }^{3}$ COWAN, 1. Mct. and C. J. GUIGUET. 1965. The Mammals of British Columbia. B.C. Prov. Museum, Dept. of Recreation and Conservation. Handbook No. 11. 546 pp.

${ }^{4} \mathrm{HALL}$, E. R. and K. R. KELSON. 1959. The Mammals of North America. Ronald Press Company. New York. Vol. 1. 546 pp.

5HUMPHREY. S. R. and J. B. COPE. 1976. Population ecology of the Little Brown Bat. Myotis lucifugus, in Indiana and north-central Kentucky.
American Society of Mammalogists Spec. Publ. 4. 81 pp.

6 MILLER, G. S. J. and G. M. ALLEN. 1928 The American bats of the gener: Myotis and Pizonyx. Bull. U.S. Nat Mus., 144. 218 pp.

7O'FARRELL, M. J. and E. H. STUDIER 1973. Reproduction, growth and development in Myotis thysanodes and $M$. lucifugus (Chiroptera: Vesper tilionidae) in northeastern Nev Mexico. American Midland Natur 93:368-376.

8RAND. A. L. 1948. Mammals of the eastern Rockies and western plains of Canada. Nat. Museum Can. Bull 108, Biol. Ser. 35. 237 pp.

9SOPER, J. D. 1964. The Mammals 0 Alberta. Queen's Printer. Edmonton 402 pp. 